\title{
LISANDUSI TEGUMOE KÄSITLUSELE ${ }^{1}$
}

\author{
MATI ERELT
}

\begin{abstract}
Annotatsioon. Kirjutises tuuakse esile eesti keele impersonaali ja passiivi järgmised omadused. Esiteks, personaalilause impersonaliseerimiseks ei piisa (inimest väljendava) täissubjekti olemasolust. See subjekt peab täitma lauses ühtlasi olulisimat semantilist rolli. Impersonaliseeritavad laused on peaaegu eranditult normaallaused (Poiss loeb raamatut). Omajalaused, kogejalaused, netsessiivlaused, tulemuslaused, samuti puht olemasolu väljendavad eksistentsiaallaused pole impersonaliseeritavad ka siis, kui neis on olemas täisalus, sest see ei ole semantiliselt esilduv (Tal on head sõbrad. - *Tal ollakse. Poistest kasvavad mehed. - *Poistest kasvatakse jms). Teiseks, ehkki implitsiitne subjekt tähistab tüüpjuhul inimest, on küllaltki tavaline muudelegi elusolenditele viitamine, ilma et sellega kaasneks isikustamist (Munad munetakse [kiilide kohta] veetaimede vartele). Kolmandaks, nagu seisundipassiivis nii ka impersonaali liitaegades võib tegevussubjekti väljendada peale poolt-adverbiaali ka adessiivadverbiaal ( $M u l$ pole sulle lilli ostetud). Ilmselt pole põhjust käsitleda adessiivadverbiaaliga konstruktsioone passiivile ja impersonaalile vastanduvate konstruktsioonidena, vaid pigem passiivsete ja impersonaalsete konstruktsioonide alltüüpidena. Neljandaks, seisundipassiiv on küll tüüpjuhul resultatiivne, kuid on olemas ka mitteresultatiivset seisundipassiivi (Suur juht on kõigi poolt armastatud).
\end{abstract}

Võtmesõnad: eesti keel, tegumood, impersonaal, seisundipassiiv, possessiivne perfekt

\section{Saateks}

Alates Henno Rajandi teedrajavast uurimusest „Eesti impersonaali ja passiivi süntaks" (1968; trükis ilmunud 1999) on eesti keele tegumoed olnud peaaegu et pideva tähelepanu all ja seega üks paremini kirjeldatud grammatikavaldkondi (vt eriti Pihlak 1993; Torn 2006; Torn-Leesik 2007, 2009; Torn-Leesik, Vihman 2010; Vihman 2004, 2007). Kui aga üritada esitada tegumoe kokkuvõtlikku käsitlust, mida siinse kirjutise autoril on

1 Uurimistööd on rahastanud SFO180084s08 ja ETFi grant 8595. 
tulnud teha eesti keele süntaksi uue tervikkäsitluse koostamise käigus, siis tuleb ikkagi ilmsiks üsna palju lahtiseid otsi ja hämaraid nurki. Järgnevas on mõnele neist püütud valgust heita. Vaadeldakse impersonaliseeritavuse vahekorda lause põhitüüpidega, impersonaali inimpiirangut, adessiivse agentadverbiaali esinemise võimalust impersonaalis ning mitteresultatiivset seisundipassiivi.

\section{Impersonaal ja lause põhitüübid}

Eesti impersonaali kirjeldustes väidetakse tavaliselt, et impersonaal ei umbisikusta mitte isiku kui sellise, vaid personaali täisalusega (nominatiivse grammatilise subjektiga) väljendatava isiku. Verbidel, millel täisalust olla ei saa, puudub ka impersonaali vorm. Sel põhjusel puudub impersonaal näiteks modaalverbil vaja olema (1), on aga olemas modaalverbil vajama (2).

(1) Neil on vaja müüjat. - *Ollakse vaja müüjat.

(2) Nad vajavad müüjat. - Vajatakse müüjat.

Modaalverbide impersonaalivõimalusi on pikemalt käsitlenud Reeli TornLeesik (2007).

Subjektilisusest üksi siiski ei piisa. Impersonaalitransformatsioon muudab implitsiitseks-indefiniitseks üksnes semantiliselt esilduva (konkreetse situatsiooni olulisimat rolli väljendava) täisaluse. Personaalilauseteks, mis sisaldavad sellist täisalust, on ennekõike normaallaused. Semantiliselt esilduvaks argumendiks on tegevussubjekt (TS) (3), selle puudumisel tegevusobjekt (TO). Tegevusobjekt esildub nn mitteakusatiivsete predikaatverbidega kaaluma, jääma jms (Torn-Leesik 2009) lausetes, kus tegevussubjekti olla ei saa (4), samuti seisundipassiivsetes lausetes, kus tegevussubjekt kas puudub või on tõrjutud tuumast perifeeriasse (5).

(3) Poiss (TS) loeb raamatut (TO). - Loetakse raamatut.

Poiss (TS) jookseb. - Joostakse.

(4) Poiss (TO) kaalub 50 kilo. - Kaalutakse 50 kilo.

(5) Nad (TO) olid võimude poolt (TS) Siberisse saadetud. - Oldi võimude poolt Siberisse saadetud.

Nad (TO) said isa käest (TS) riielda. - Saadi isa käest riielda. 
Impersonaalne eksistentsiaallause on loomulik juhul, kui selle predikaat ei väljenda ainult olemasolu, vaid ka mingit tegevust (6) või protsessi (7). Vrd

(6) Seal karjub keegi. = Seal karjutakse.

(7) Seal on keegi. $\neq$ Seal ollakse.

Konkreetse tegevus- või protsessitähenduse puudumine ei lase eksistentsiaallauses moodustada impersonaalivormi verbist puuduma (8), pelk olemasolutähendus ja subjekti partsiaalsus ei luba seda aga verbidest leiduma (9), piisama ja jätkuma (10).

(8) Lätis puudub karismaatiline president. - *Lätis puudutakse.

(9) Eestis leidub andekaid noori. - *Eestis leidutakse.

(10) Teda jätkus kõikjale. - *Jätkuti kõikjale.

Muudes lausetüüpides takistab impersonaali moodustust asjaolu, et tegevussubjekt ei ole täisalus, vaid määrus või sihitis. Täisalus, kui see lauses üldse esineb, on tegevusobjekt. Seetõttu pole võimalik impersonaliseerida omajalauset, kus tegevussubjektiks on adverbiaal, täisalus aga vormistab tegevusobjekti (11). Kumbagi argumenti pole võimalik indefiniitseks muuta. Küll aga saab impersonaliseerida normaallauset, kus omamist väljendab spetsiaalne omamisverb omama, sest siin vormistub omajast tegevussubjekt täisalusena (12).

(11) Tal on head sõbrad. $\neq$ Ollakse head sõbrad. - *Tal ollakse.

(12) Ta omab häid sõpru. - Omatakse häid sõpru.

Samamoodi käituvad vajalikkust väljendava predikaadiga laused. Nagu juba öeldud, on võimalik umbisikustada näiteks normaallauseid predikaadiga vajama, kus tegevussubjekti vormistab täisalus, mitte aga netsessiivlauseid adessiivset tegevussubjekti nõudva predikaadiga olema vaja. Nii nagu on vaja, nõuavad alati adessiivset argumenti ka modaalverbid olema tarvis (13) ja tulema (14) ning seetõttu puuduvad neil impersonaalivormid (Torn-Leesik 2007: 183).

(13) Neil on tarvis müüjat. - *Ollakse tarvis müüjat.

(14) Neil tuleb lahkuda. - *Tullakse lahkuda.

Adessiivset tegevussubjekti eelistavad ka modaalverbide tarvitsema ja pruukima jaatavad vormid, mistõttu nende impersonaalivorm on võrdlemisi haruldane. Reeli Torn-Leesiku arvates (2007: 183) on see koguni võimatu. Pille Penjam (2011) on siiski näidanud, et päris võimatu alus ja 
impersonaal siiski pole. Seevastu modaalverbide tarvitsema ja pruukima eitavad vormid esinevad grammatilise subjektiga üsna sageli ja on tavalised ka impersonaalis (15).

(15) Kas tõesti filosoofia võib olla ühe mõtleja teostes ja loomingus tervenisti olemas, et tarvitsetakse selle ühe kaudu sisse juhatada? [t] ${ }^{2}$ (Penjam 2011: 516) X-teega võib liitunud olla tuhandeid andmekogusid, millest sugugi kõiki igas portaalis ei tarvitseta kasutada. [t] (Penjam 2011: 516)

Impersonaliseerida ei saa ka tulemuslauseid, mille tegevussubjekt on elatiivadverbiaal (16), küll aga samasisulist normaallauset (17). Vrd

(16) Poistest kasvasid mehed. - *Poistest kasvati.

(17) Poisid kasvasid meesteks. - Kasvati meesteks.

Ka kogejalauset, mille grammatiliseks subjektiks pole mitte kogeja-, vaid stiimulargument, pole harilikult võimalik umbisikustada, sest tavaliselt tõlgendatakse just kogejat protsessi aktiivsema poolena, seega tegevussubjektina. Täiesti välistatud on impersonaal korduvalt näiteks toodud verbi huvitama puhul (18) (Rajandi 1999: 88).

(18) Tüdrukud huvitavad poisse. - *Huvitatakse poisse.

Verbide vihastama, rõõmustama, kurvastama jne puhul on impersonaalitransformatsioon võimalik ainult sel juhul, kui subjektisik tõlgendub tahtlikult toimivana, seega normaallause agendina, mitte stiimulina (19).

(19) Tüdrukud vihastavad / rõõmustavad / kurvastavad poisse. - Vihastatakse / rõomustatakse / kurvastatakse poisse.

Mõne kogemispredikaadi, nagu meeldima ja meenuma puhul võib ilmselt mõnikord harva ka stiimul tegevussubjektina tõlgenduda ja verbi umbisikulisust lubada, Torn-Leesiku märkamist mööda eriti retsiprookses konstruktsioonis (20).

(20) Kerge keerutamine, et ma ise peaks ka hakkama huvi tundma, ja kui on juba näha, et meelditakse üksteisele, pole mõtet enam keerutada. (neti) Ja siis astutakse tuppa ja vaadatakse üksteist kui võõraid. Ühel hetkel aga meenutakse üksteisele. (Torn-Leesik 2009: 81)

2 Siin ja edaspidi tähistavad [t], [i] ja [a] näidete järel vastavalt Tartu Ülikooli kirjakeelekorpuse teadus-, ilukirjandus- ja ajakirjandustekste. 


\section{Kas umbisik on ainult inimene?}

Tavaliselt väidetakse, et impersonaali indefiniitne referent on tüüpjuhul inimene, erandjuhul personifikaat, s.o isikustatud olend või mitteolend (kui tegemist on ainult inimesele omase tegevusega). Harilikult personifitseeritakse loomi (21), loodusjõude või loodusprotsesside oletatavaid sooritajaid (22) või keerulisi seadmeid (justnagu inimese pädevusega toimivaid seadmeid, mõtlevaid masinaid (23). (EKK 2007: 453-454) Verbid, mis väljendavad muudele elusolenditele omast tegevust, saavad impersonaalis metafoorse tõlgenduse (24) (Torn-Leesik 2009: 77-78).

(21) Metsas peeti lõvi eesistumisel koosolekut.

(22) Laev paisati kaldale. Puud kisti juurtega maast välja. | Sellel suvel oli Eestimaal suur torm, murti maha palju puid ning laastati kasvuhooneid [a]. Sidrunimahlas leiduvad happed reageerivad rasvaga ja selle tulemusena moodustuvad vesilahustuvad keemilised ühendid - estrid, mis veega loputamisel ära uhutakse [a]. Vaheosakestel saab selline seos kehtida vaid juhul, kui tema tekke- ja kaduprotsessides rikutakse energia jäävuse seadust [a].

(23) Word jaotab arvutisse sisestatud teksti lehekülgedeks vastavalt lehekülje mõõtmetele. Kui üks lehekülg on tekstiga täidetud, alustatakse uuega [a].

(24) Briti parlamendis hüütakse, naerdakse, määgitakse rääkijale vahele. [a]

Impersonaali kasutustingimused on siiski natuke laiemad. Umbisik võib olla ka muu elusolend kui inimene. Seda niihästi siis, kui sellele on tüüpiline sama tegevus mis inimesele (söömine, magamine, jooksmine vm), mispuhul võiks ehk oletada mingil määral inimteguri mõju (25), kui ka siis, kui tegemist on tegevusega, mis inimesele kas üldse või kuigi tavaline pole (26). Mõlemat tüüpi näiteid on üle ootuste palju.

(25) Keegi jääb huntide kätte ja süüakse ära [a]. Poegade arv on seega väga väike - reeglina alla kümne järglase ühe emase elevandi elu jooksul, kuid iga järglase eest hoolitsetakse ülipõhjalikult. [t] Suurem osa kutsikaid jätkab sama tegevust, mis uru juures - ronitakse keset välja asetseva külmakerke künka otsa ja üritatakse üksteist sealt alla nügida. [t]

(26) Meie külas olen veel mõnda koera näinud, suuremates linnades - ka Naganos - haugutakse haruharva [a]. Suvisel ajal, kui kaljukotkastel poeg pesas on, otsitakse saaki lähematelt aladelt - siis on ka toiduvalik suurem, talvel aga lennatakse rohkem ringi. [t] Pesitsetakse [roosakajakas] kas üksinda või enamasti kuni 5 paariliste kolooniatena. [t] Munad 
munetakse [kiilide kohta] veetaimede vartele, vastseiga kestab ühe aasta. [t] Teises akvas $24 \mathrm{C}$ juures kooruti [kuldkalad] eile ehk neljandal päeval. [t]

\section{Agentadverbiaal impersonaalis}

Henno Rajandi näitas oma tegumoeuurimuses (1968/1999), et impersonaali tegevussubjekti võib väljendada agentadverbiaal kujul Ngen + poolt või elatiivis. Poolt-adverbiaal (27) on impersonaalis tavaline, selle kasutustingimusi on põhjalikult käsitlenud Reeli Torn-Leesik (eriti Torn 2006). Korpusest ei õnnestunud aga leida impersonaali elatiivse agentadverbiaali kohta selget näidet (lihtaegades või liitaegade puhul partitiivse objektiga). Ka Rajandi näide (28) tundub kunstlikuna. Küll aga on elatiivne adverbiaal loomulik seisundipassiivi korral (29).

(27) Mahetooteid hinnatakse tarbijate poolt.

(28) ?Frakk pureti koidest auklikuks. (Rajandi 1999: 81)

(29) See olevat küll paarist kohast koidest puretud ja luitunud ning aja jooksul kokku tõmbunud nagu kõik riideesemed, mida ei kanta. [a]

Samas leidub täiesti loomulikke näiteid adessiivse agentadverbiaali kohta impersonaalis, mida Rajandi peab võimalikuks ainult passiivis. Selliseid näiteid pakuvad ka Liina Lindströmi ja Ilona Trageli (L-T) uurimused $(2007,2010)(30)$.

(30) Aga Eval on midagi veel krõbedamat minu jaoks varutud. (L-T 2007: 546) Meil ei ole veel tehtud süvaanalüüsi, aga ... (L-T 2010: 382) Kui kellelgi magu üles ütleb, siis $m u l$ on Rennie tablette ostetud. (L-T 2010: 382)

Et tegemist on impersonaaliga, mitte seisundipassiiviga, seda näitab objekti partsiaalsus jaatuse või eituse korral. Adessiivne agentadverbiaal on impersonaalis võimalik ainult liitaegades, s.o perfektiivse tähenduse korral. Adessiivadverbiaaliga seisundipassiivsete lausete puhul jõudsid Lindström ja Tragel $(2007,2010)$ seisukohale, et niisugused tud-partitsiibiga ja agendile (TS) osutava topikuga laused on hoopis omaette konstruktsioon, mida nad eriti Heine ja Kuteva (2006: 140-182) eeskujul nimetasid possessiivseks perfektiks. Algselt olevat sellised konstruktsioonid väljendanud kahte sündmust, nt lause $M u l$ on auto pestud puhul: I Mul on auto; II Auto on pestud. Esimesest pärineb possessiivsus, teisest 
perfektiivsus. Hiljem kujunes sellest konstruktsioonist ühtainsat sündmust väljendav tarind, milles omaja on ühtlasi agent ja tarindi ülesandeks sai väljendada agendi tegevuse lõpetatust, agendi seisundit, mitte patsiendi (TO) seisundit, nagu algselt passiivi puhul (Auto on pestud). Patsienti ei pruugi tarindis ollagi - konstruktsioon on ilmselt transitiivse vaheastme kaudu laienenud ka intransitiivsete verbidele, nt $\mathrm{Mul}$ on magatud. Mul on poes käidud.

Kuivõrd Lindströmi-Trageli järgi saab patsient possessiivse perfekti puhul olla ainult subjekt, jäävad selge objektiga laused (30) possessiivse perfekti alt ilmselt välja. Samas on nende sarnasus subjektiliste lausetega nii possessiivsuse kui ka perfektiivsuse aspektist üsnagi suur.

Lindströmi-Trageli käsitluse juures häirib mõnevõrra ka see, et infostruktuurile on jäetud passiivi ja possessiivse perfekti eristuses väga oluline roll. Nii peavad nad lauset Mul on auto pestud possessiivseks perfektiks, lauset Auto on mul pestud aga seisundipassiiviks.

Tekib küsimus, kas on päris õige käsitleda possessiivset perfekti seisundipassiivile ja impersonaalile vastanduva konstruktsioonina. Kas poleks õigem rääkida possessiivsest resultatiivsest passiivist ja possessiivsest impersonaalist kui passiivi ja impersonaali alltüüpidest? Uut kaalumist vajab ehk seegi, kas lähtumine possessiivsest konstruktsioonist ( $\mathrm{Mul}$ on auto) on ikka ainuke võimalus nende konstruktsioonide seletamiseks (kriitikat selle kohta vt nt Seržant 2012).

\section{Resultatiivne ja mitteresultatiivne seisundipassiiv}

Meie tegumoekäsitlustes on seisundipassiivi millegipärast ainult resultatiivseks peetud ja seetõttu termineid seisundipassiiv ja resultatiivne passiiv lausa sünonüümidena kasutatud. Päris täpne see siiski pole. Lause Uksed olid suletud väljendab tõepoolest tulemusseisundit, kuid näiteks vaimset seisundit väljendavate verbide armastama, vihkama, põlgama, kartma, tundma, hindama jms passiivi puhul ei saa rääkida seisundist kui eelneva protsessi tulemusest. Seisund on siin ka enne olnud seisund. $\mathrm{Nt}$

(31) АктіIV: Kõik armastavad/vihkavad suurt juhti.

(32) PAssiv: Suur juht on kõigi poolt armastatud/vihatud. | .. paljud praegused töötud kultuuriloojad olid ikkagi nimelt nõukogude ajal eriti populaarsed ja rahva poolt armastatud olnud. [i] Lõtkini teadustööd on mongolistidest kolleegide poolt hinnatud tänini. [t] 
Üks sellise passiivi tunnuseid on see, et selle puhul ei kasutata mata-eitust.

(33) *Suur juht on kõigi poolt armastamata.

Täpsem oleks seega seisundipassiivi mitte võrdsustada resultatiivse passiiviga, vaid eristada resultatiivset ja mitteresultatiivset seisundipassiivi.

\section{Kokkuvõte}

Eelneva põhjal võib öelda järgmist.

- Impersonaali implitsiitne subjekt peab olema semantiliselt esilduv, s.o situatsiooni olulisimat semantilist rolli väljendav täisalus. Väheste eranditega on impersonaliseeritavad laused normaallaused. Omajalaused, kogejalaused, netsessiivlaused, tulemuslaused, samuti puht olemasolu väljendavad eksistentsiaallaused pole impersonaliseeritavad ka siis, kui neis on olemas täisalus, sest viimane ei ole semantiliselt esilduv.

- Ehkki implitsiitne subjekt tähistab tüüpjuhul inimest, on küllaltki tavaline muudelegi elusolenditele viitamine, ilma et sellega kaasneks isikustamist.

- Nagu seisundipassiivis nii ka impersonaali liitaegades võib tegevussubjekti väljendada peale poolt-adverbiaali ka adessiivadverbiaal. Ilmselt pole põhjust käsitleda adessiivadverbiaaliga konstruktsioone passiivile ja impersonaalile vastanduvate konstruktsioonidena, vaid pigem passiivsete ja impersonaalsete konstruktsioonide alltüüpidena.

- Seisundipassiiv on küll tüüpjuhul resultatiivne, kuid on olemas ka mitteresultatiivset seisundipassiivi.

\section{Kirjandus}

EKK 2007 = Mati Erelt, Tiiu Erelt, Kristiina Ross. Eesti keele käsiraamat. Kolmas, täiendatud trükk. Tallinn: Eesti Keele Sihtasutus.

Heine, Bernd, Tania Kuteva 2006. The Changing Languages of Europe. Oxford: Oxford University Press. http://dx.doi.org/10.1093/acprof: oso/9780199297337.001.0001.

Lindström, Liina, Ilona Tragel 2007. Eesti keele impersonaali ja seisundipassiivi vahekorrast adessiivargumendi kasutamise põhjal. - Keel ja Kirjandus 7, 532-553. 
Lindström, Liina, Ilona Tragel 2010. The possessive perfect construction in Estonian. - Folia Linguistica 44 (2), 371-399. http://dx.doi.org/10.1515/ flin.2010.014.

Penjam, Pille 2011. Eesti kirjakeele subjektilised ja adessiivadverbiaaliga tarvitsema konstruktsioonid. - Keel ja Kirjandus 7, 505-525.

Pihlak, Ants 1993. A Comparative Study of Voice in Estonian. (= Eesti Sisekaitse Akadeemia Toimetised 1.) Tallinn.

Rajandi, Henno 1999. Eesti impersonaali ja passiivi süntaks. (= Eesti Keele Instituudi toimetised 3.) Tallinn. Käsikirjalise kandidaadiväitekirja (1968) trükk.

Seržant, Ilja A. 2012. The so-called possessive perfect in North Russian and the Circum-Baltic area. A diachronic and areal account. - Lingua 122 (4), 356-385. doi:10.1016/j.lingua.2011.12.003.

Torn, Reeli 2006. poolt-tarind eesti keele impersonaalis ja passiivis. - Lause argumentstruktuur. (= Tartu Ülikooli eesti keele õppetooli preprindid 2.) Tartu, 108-121.

Torn-Leesik, Reeli 2007. Voice and modal verbs in Estonian. - Linguistica Uralica XLIII (3), 173-186.

Torn-Leesik, Reeli 2009. The voice system of Estonian. - Estonian in typological perspective. Ed. Helle Metslang. (= Language Typology and Universals. Sprachtypologie und Universalienforschung (STUF) 62 (1/2).) Berlin: Akademie Verlag, 72-90. http://dx.doi.org/10.1524/stuf.2009.0005.

Torn-Leesik, Reeli, Virve-Anneli Vihman 2010. The uses of impersonals in spoken Estonian. - SKY Journal of Linguistics 23, 301-343.

Vihman, Virve-Anneli 2004. Valency Eduction in Estonian. Ph.D. dissertation. University of Edinburgh.

Vihman, Virve-Anneli 2007. Impersonaliseeritud impersonaal kui konstruktsioonitasandi grammatisatsioon. - Emakeele Seltsi aastaraamat 52 (2006). Tallinn, 158-178. 


\title{
Some additions to the treatment of voice
}

\author{
Mati Erelt
}

The article focuses on the following characteristics of the impersonal and the passive in Estonian. First, the presence of a total subject (denoting a human) is not sufficient for impersonalization of a personal clause. This subject must perform at the same time the most salient semantic role. Impersonalized clauses are normal clauses (Poiss loeb raamatut 'the boy is reading a book') almost without exception. Possessive, experiential, necessive, and resultative clauses, as well as pure existential clauses, cannot be personalized even if they include a total subject because it is not semantically salient (Tal on head sõbrad 'he has good friends' - *Tal ollakse. Poistest kasvavad mehed 'boys grow up to become men' *Poistest kasvatakse etc.). Second, although an implicit subject typically denotes a human referent, references to other animate beings are rather common without any accompanying personification (Munad munetakse veetaimede vartele 'eggs are laid (of dragonflies) on the stalks of water plants'). Third, similarly to the stative passive, in the compound tenses of the impersonal, too, the actor could be expressed in addition to an agentive phrase with the postposition poolt 'by' also by an adessive phrase (Mul pole sulle lilli ostetud 'I haven't bought any flowers for you'). Apparently, there is no good reason to regard constructions with adessive phrases as constructions contrasting with the passive and the impersonal; rather, they should be regarded as subtypes of the latter. Fourth, the stative passive is typically resultative; however, there exists also non-resultative stative passive (Suur juht on kõigi poolt armastatud 'the great leader is loved by everyone').

Keywords: Estonian language, voice, impersonal, stative passive, possessive perfect

\author{
Mati Erelt \\ eesti ja üldkeeleteaduse instituut \\ Tartu Ülikool \\ Jakobi 2 \\ 51014 Tartu \\ mati.erelt@ut.ee
}

